\title{
Role of Adult Asthma Education in Improving Asthma Control and Reducing Emergency Room Utilization and Hospital Admissions in an Inner City Hospital
}

\author{
Rashmi Mishra, ${ }^{1}$ Muhammad Kashif, ${ }^{1}$ Sindhaghatta Venkatram, ${ }^{1}$ Teresa George, \\ Kristina Luo, ${ }^{2}$ and Gilda Diaz-Fuentes ${ }^{1}$ \\ ${ }^{1}$ Division of Pulmonary and Critical Care, Bronx-Lebanon Hospital Center, Bronx, NY, USA \\ ${ }^{2}$ Department of Pharmacy, Bronx-Lebanon Hospital Center, Bronx, NY, USA \\ Correspondence should be addressed to Muhammad Kashif; drkashif178@gmail.com
}

Received 19 February 2017; Accepted 2 April 2017; Published 4 May 2017

Academic Editor: Angelo G. Corsico

Copyright (c) 2017 Rashmi Mishra et al. This is an open access article distributed under the Creative Commons Attribution License, which permits unrestricted use, distribution, and reproduction in any medium, provided the original work is properly cited.

Objective. Asthma education programs have been shown to decrease healthcare utilization and improve disease control and management. The purpose of our study was to evaluate the impact of an outpatient adult asthma education program in an inner city hospital caring for patients with low socioeconomic and educational status. Methods. An asthma education program was implemented in September 2014. Patients who received education from September 2014 to July 2015 were evaluated. Outcomes were compared for the same group of patients before and after education. Primary outcomes were emergency room (ER) visits and hospital admissions. Secondary outcomes were change in Asthma Control Test (ACT) score and number of pulmonary clinic visits. Results. Asthma education significantly decreased number of patients requiring ER visits and hospital admissions $(p=0.0005$ and $p=0.0015$, resp.). Asthma control as per ACT score $\geq 20$ improved with education $(p=0.0001)$ with an increase in clinic visits $(p=$ $0.0185)$. Conclusions. Our study suggests that implementation of a structured asthma education program in an inner city community hospital has a positive impact on reduction of ER visits and hospital admissions with improvement in asthma control. Institutional Review Board Clinical Study registration number is 01081507.

\section{Introduction}

According to the National Health Interview Survey of 2014, approximately 30 million people had been diagnosed with asthma in their lifetime. 17.7 million (7.4\%) adults still have asthma; out of these, around 7 million (43.6\%) suffered from asthma attacks in 2014 [1]. The number of patients with asthma increased by $28 \%$ from 2001 to 2011 [2]. The estimated total cost of asthma to society was $\$ 56$ billion (2009 dollars) in 2007. This included medical expenses, loss of productivity resulting from missed school or work days, and premature death [2].

The Global Initiative for Management and Prevention of Asthma (GINA) guidelines were developed to improve the care and control of the disease [3]. Asthma education is recommended for all children and adults as part of management [3]. Multiple studies have shown that education improves outcomes like asthma-related emergency room (ER) utilization and hospitalization, unscheduled physician visits, days off work, and quality of life (QoL) [4]. Studies showing improvement in QoL and decreased ER utilization and hospitalization utilized multiple education sessions over few months [4-7].

Low socioeconomic status is associated with asthma and respiratory symptoms [8]. Inadequate home characteristics, exposure to environmental tobacco smoke, air pollution, and sustained exposure to indoor and outdoor pathogens are some factors that have been associated with development of respiratory diseases in this population [9-14]. Lack of asthma education as a contributor to the poor control of asthma in an inner city population has not been clearly described. Bronx county in NYC ranks lowest among all 62 counties in New 


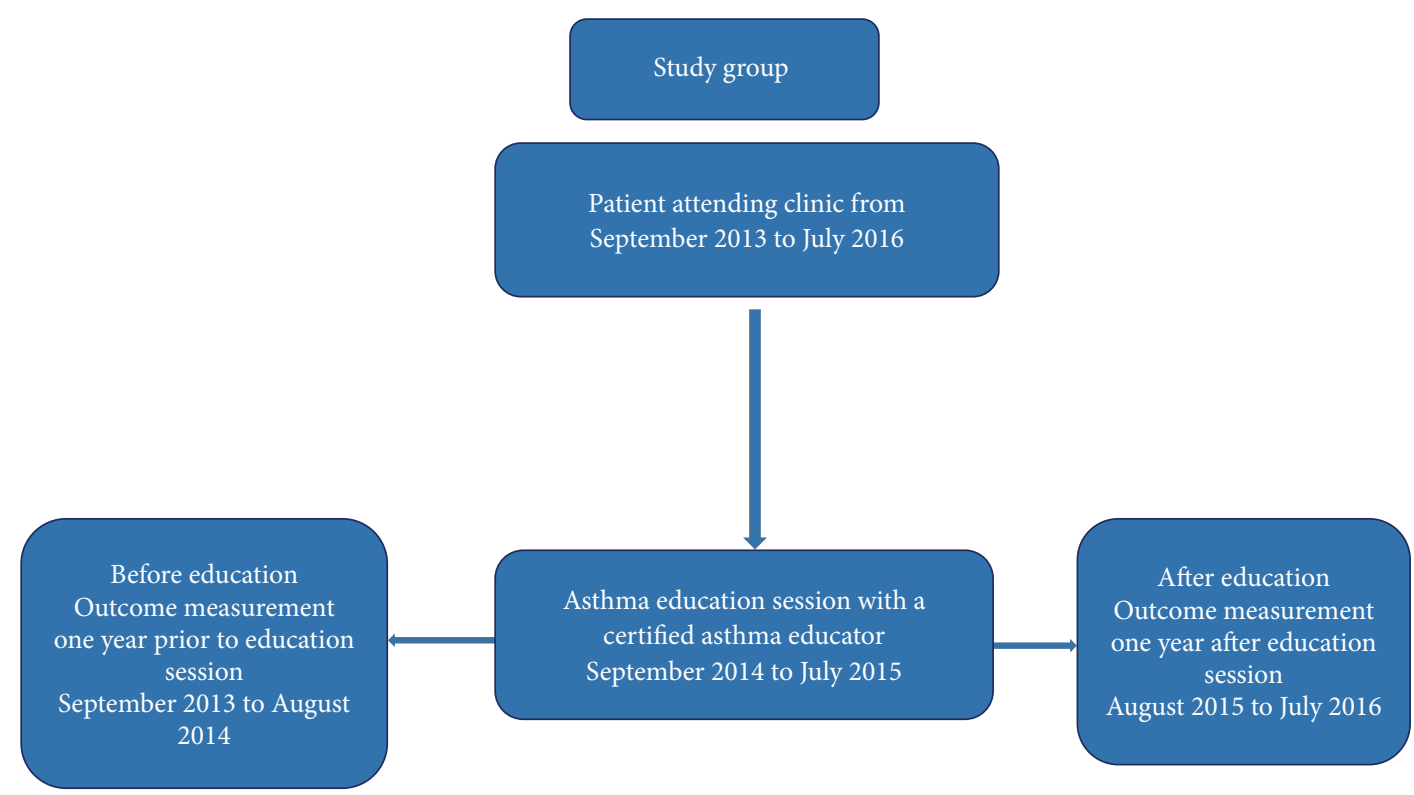

FIgURE 1: Study design.

York state in all of the following domains: health outcomes, $62 / 62$, health factors, 62/62, clinical care, 62/62, social and economic factors, 62/62 (high school, 60\%; some college, $50 \%$ ), and physical environment, 62/62. [15]. This county has large minority and immigrant populations. Demographics are distinct with large minority and immigrant populations with low socioeconomic status, as indicated by education, employment, and homelessness rates. The prevalence of asthma in this group is one of the highest in the country. Bronx-Lebanon Hospital Center (BLHC) is in South Bronx and serves a large population with asthma. We aimed to evaluate the role of an asthma education program in the control of asthma in our inner city patient population.

\section{Materials and Methods}

This was a pre-and-post study of all asthmatic patients managed in the pulmonary clinic. The study period was from September 2013 to July 2016. An asthma education program was implemented in September 2014 and includes on-site certified asthma educators.

We included all asthmatic patients that participated in structured asthma education from September 2014 to July 2015 and had clinic follow-up until July 2016.

Outcomes were compared for the same group of patients during the preeducation period (September 2013 to August 2014) and the posteducation period (August 2015 to July 2016) (Figure 1).

Approval for this study was obtained from the Institutional Review Board (IRB) of Bronx Lebanon Hospital (IRB \# 01081507).

2.1. Primary Outcomes Included. Primary outcomes included the following:

(1) Number of patients requiring ER visits during the preeducation and posteducation periods
(2) Number of patients requiring hospital admission during preeducation and posteducation periods. In addition to ER or hospitalization at our institution, we included patients' reports of other ER visits or hospitalization due to asthma.

2.2. Secondary Outcomes Included. Secondary outcomes included the following:

(1) Change in asthma control assessed by the Asthma Control Test (ACT) score at visit following the asthma education

(2) Number of pulmonary clinic visits during preeducation and posteducation periods

Multiple ER visits or admissions were defined as more than one ER visit or hospitalization for asthma during the study period.

2.3. Structure of the Asthma Education Program. The asthma educators included two on-site certified asthma educators, a bilingual (English and Spanish) respiratory therapist and a clinical pharmacist. The education was done in the patient's preferred language with help of interpreter services, if required. Translator phone services are available.

The education sessions consisted of a personalized (oneto-one) 30-minute sessions with an asthma educator.

Documentation in the electronic medical record (EMR) followed a structured asthma education note. This form captures data including demographics, ACT score, medications, adherence with medications, and asthma action plan.

The education sessions usually followed the visit to the pulmonologist.

On-site spirometry was performed as per the discretion of the physician. 
All patients received written education material available in English and Spanish. Those materials were created following national guidelines and included basic definition of asthma, disease management and control, medications pictures and descriptions, role of peak flow, and environmental control and trigger.

The goals of the education session consisted of having the patient understand the following:

(1) What is asthma?

(2) Disease management and control

(3) Adequate and appropriate use of inhalers, spacers, and peak flow meter

(4) Review of written educational materials

(5) Asthma action plan

At the end of the session, patients were required to be able to demonstrate appropriate use of inhalers and peak flow meter.

2.4. Statistical Analysis. The analysis utilizes preeducation and posteducation data. The sample population of this study consisted of a total of 231 patients. Only those patients who were followed up at clinic one year prior to and one year after education were included. Institutional medical records were reviewed to assess number of hospitalization incidences, ER visits, asthma control score, and asthma severity in the preintervention and postintervention periods. We evaluated documentation including patient reporting ER or hospital admissions to other institutions. Patients who were lost to follow-up after intervention were excluded.

IBM SPSS v19.0 was used for statistical analysis.

The number of patients requiring ER visits and hospitalization were calculated using unpaired $t$-tests. The average numbers of ER visits and hospitalization incidences were calculated using "Compare means" analysis of IBM SPSS. The effect of asthma education on asthma control evaluated using ACT score was compared with the help of unpaired $t$-test. The number of clinic visits was compared using unpaired $t$-tests.

\section{Results}

3.1. Demographic Data. 250 patients participated in initial education; 19 patients were excluded as they were lost in follow-up. 231 patients were analyzed. Table 1 shows the baseline characteristics of the patients.

Distribution of the severity of asthma was as follows: $2.6 \%$ intermittent, $23.8 \%$ mild, $53.7 \%$ moderate, and $19.9 \%$ severe persistent. At least a third of our patients had comorbid conditions: psychiatric illness followed by gastroesophageal reflux and obesity were the most common (Table 1). Anxiety and depression accounted for majority of psychiatric diseases.

$132(56.7 \%)$ of the 231 patients were given an asthma action plan during education. 50 patients (22\%) received more than one education session, $42(18 \%)$ received two sessions, $9(4 \%)$ received three sessions, and one $(0.4 \%)$ received four education sessions.
TABLE 1: Baseline clinical and demographic characteristics.

\begin{tabular}{lc}
\hline Characteristics & $n=231$ \\
\hline Age, year (average \pm SD) & $53.28 \pm 15.84$ \\
Gender, female & $176(76.2 \%)$ \\
Race & \\
Black & $67(29 \%)$ \\
Hispanic & $115(49.8 \%)$ \\
Tobacco, active cigarette smoker & $57(24.7 \%)$ \\
BMI \pm SD & $31.85 \pm 7.13$ \\
Severity of persistent asthma & \\
Mild & $55(23.8 \%)$ \\
Moderate & $124(53.7 \%)$ \\
Severe & $46(19.9 \%)$ \\
Comorbidities & \\
Obstructive sleep apnea & $34(14.7 \%)$ \\
Pulmonary hypertension & $23(9.9 \%)$ \\
Gastroesophageal reflux & $66(28.6 \%)$ \\
Psychiatric illness on medication & $72(31.2 \%)$ \\
Congestive heart failure & $23(9.9 \%)$ \\
Ischemic heart disease & $20(8.6 \%)$ \\
Chronic renal disease & $20(8.6 \%)$ \\
Allergic rhinitis & $9(3.9 \%)$ \\
FEV1/FVC < 70 & $61 / 186(32.8 \%)$ \\
\hline
\end{tabular}

3.2. Primary Outcomes. During the post-asthma-education period, there was a significant decrease in the number of patients requiring ER visits as compared to preeducation period [preeducation $(n=94)$ and posteducation $(n=60)$; $p=0.0005,95 \% \mathrm{CI}$. Asthma education also reduced the number of patients requiring hospitalization [preeducation $(n=49)$ and posteducation $(n=26) ; p=0.0015,95 \% \mathrm{CI}]$.

We also found a significant decrease in the average number of ER visits per patient/year [0.91 (preeducation) to 0.61 (posteducation) $(p=0.04,95 \% \mathrm{CI})]$ and in the average number of hospital admissions per patient/year [0.34 (preeducation) to 0.19 (posteducation) $(p=0.0015,95 \% \mathrm{CI})$ ].

A subset evaluation of patients with more than one ED visit or hospital admission showed no impact of asthma education (Table 2).

3.3. Secondary Outcomes. The effect of education on asthma control was evaluated using an ACT score $\geq 20$ as per GINA guidelines. Patients without preeducation and posteducation ACT score were excluded from analysis. 126 (55\%) patients had ACT score available. Asthma education had a statistically significant $(p=0.0001,95 \% \mathrm{CI})$ effect on the number of asthmatics with ACT score $\geq 20(n=20,15.8 \%$ before education, versus $n=44,34.9 \%$ after education) (Table 2 ).

There was a change in number of clinic visits during the preeducation and posteducation periods $[1.76$ (preeducation) versus 2.18 (posteducation) $(p=0.01,95 \% \mathrm{CI})]$.

\section{Discussion}

In this study, we found that a comprehensive asthma education program in an inner city asthmatic group decreased 
TABLE 2: Main study outcomes.

\begin{tabular}{|c|c|c|c|}
\hline Outcomes & $\begin{array}{c}\text { Before education } \\
n=231\end{array}$ & $\begin{array}{c}\text { After education } \\
n=231\end{array}$ & $p$ value \\
\hline Number of patients requiring ER visits & 94 & 60 & 0.0005 \\
\hline Number of patients requiring hospitalization & 49 & 26 & 0.0015 \\
\hline Average number of ER visits/patient/year & $0.91 \pm 1.748$ & $0.61 \pm 1.401$ & 0.04 \\
\hline Average number of admissions/patient/year & $0.34 \pm 0.87$ & $0.19 \pm 0.70$ & 0.0015 \\
\hline Average ICU admission/patient/year & $0.03 \pm 0.183$ & $0.03 \pm 0.195$ & 0.7637 \\
\hline Number of patients with controlled asthma $(\mathrm{ACT} \geq 20)$ & $20(N=126)$ & $44(N=126)$ & 0.0001 \\
\hline Average number of clinic visits/patient/year & $1.76 \pm 2.51$ & $2.18 \pm 2.40$ & 0.0185 \\
\hline Number of patients with $>1$ ER visits/year & 41 & 31 & 0.7087 \\
\hline Number of patients with $>1$ admission/year & 14 & 8 & 0.7202 \\
\hline
\end{tabular}

hospital and ER utilization and improved asthma control as assessed by the ACT score. To our knowledge, this is one of the first studies using a short education session incorporated to the same day clinic visit.

Improved asthma outcomes with education have been reported in other socially deprived populations like ours. De Oliveira et al. conducted a study in Brazil to evaluate the effectiveness of asthma education. 53 asthmatic patients were studied: 26 in the education and 27 in the control group. Monthly education provided for six months resulted in decreased ER visits and better symptoms control and scores on QoL questionnaire; however, there was no reduction in hospital admissions [7]. We attempted to eliminate potential environmental confounders and triggers that arise when comparing different patients; so we compared same patients, assuming that triggers and leaving conditions remained stable.

One of the purposes of personalized and structured education is to highlight the importance of each patient's ethnic and socioeconomic background. The presence of inadequate health literacy has not been associated with difficulty in learning or retaining inhaler technique [16]. Asthma education should be tailored to the specific ethnic groups considering cultural differences. In a study done in UK among different ethnic groups of white Europeans and Indians, a significant decrease in physician visit, hospitalization, and use of corticosteroids and antibiotics occurred in only the white European population but not in Indians [17]. In another study among Chinese and Punjabis, an improvement in knowledge of asthma symptoms, inhaler use, and understanding of physician's instructions over 3 months after asthma education is reported. The program included watching education videos or reading educational pamphlets [18]. In our program, interpreter services were used if required in order to educate patients in their preferred language. Less than $2 \%$ of our patients spoke other languages but English or Spanish.

Some studies report better outcomes in asthma with the use of the asthma action plan $[3,4]$. Asthma action plan is highly recommended in addition to education in the GINA guidelines to improve outcomes in asthmatics. The Cochrane review found that self-management of asthma using a written action plan based on peak expiratory flow rates was equivalent to using symptoms based written action plan [19].

When patients with more than one visit to ER or more than one hospitalization incidence were evaluated, we found no outcome benefits from the education program. Possible explanations for the failure of education in this subgroup include (a) ineffective education sessions, (b) use of ER to obtain medications, (c) lack of "off hours" ambulatory services, (d) presence of comorbid conditions, and (e) lack of insurance. An additional asthma education session for reinforcement may be beneficial in these patients. There was no difference in clinical and baseline characteristics of this subgroup. The three most common comorbid conditions in our asthma cohort were psychiatric conditions, GERD, and OSA. In one study, $9.7 \%$ of asthmatics suffered from anxiety and $9 \%$ suffered from depression as compared to $6.6 \%$ and $5.5 \%$ prevalence, respectively, among nonasthmatic patients [20]. There is inconclusive data regarding the use of relaxation therapy to improve medication adherence, cognitive behavioral therapy to improve QoL, and use of biofeedback to improve peak expiratory flow in asthmatics [21].

Asthma Control Test is a well-validated tool to assess poorly controlled asthma as defined by GINA guidelines [22]. The ACT score is likely the simplest and widely used test to assess asthma control and evaluate the effectiveness of asthma education. Another method to evaluate asthma control is maintenance of a diary by the patient which can be tedious and patient compliance is a potential barrier. Mehuys et al. showed improved ACT scores after implementation of pharmacist-led asthma education program [23].

Improving asthma control and decreasing ER visits and hospitalization could have beneficial effect in healthcare cost and patient care. Yilmaz and Akkaya showed a decrease in ER visits and improved QoL scores in a small group of patients after six education sessions over one year [6]. Urek et al. compared the use of individual verbal instruction (three one-hour sessions) with written asthma information (asthma booklet) and with asthma group classes (four hours of group education) in 60 adults with moderate persistent asthma during a three-month follow-up. They reported that asthma group classes and individual verbal education improved QoL and asthma control [24].

There are many barriers in our inner city community for implementation of education sessions during prolonged period as used in other trials. Those potential barriers include financial and time constraints to return to clinic for education and perception of low value to education in disease management. In settings where education is provided solely by the physician, time constraints, lack of reimbursement, and 
proper training in education are potential barriers. Our study shows that a single education session linked to the physician visit has a positive impact on asthma control and healthcare utilization.

Strengths. This study evaluated the impact of an asthma education program as part of the physician visit in an inner city population with socioeconomic disadvantages. Implementation of a single session requires less institutional support and can be well and easily standardized and incorporated within physician visit. In our center, incorporation of a respiratory therapist and a clinical pharmacist helps us to fill other needs of patient care like performance of pulmonary functions test and medication evaluation and management.

Limitations. These include limitations of a pre-post retrospective study including selection bias toward patients with difficult-to-control asthma or poor adherence to care. In addition, it is difficult to separate the effect of physician influence during the visit. Unless patients reported ER visits or hospitalization to other hospitals but BLHC, this data was not captured. In general, our population tends to seek care at their main hospital. Although correct use of inhaler was evaluated at the end of asthma education session, documentations by providers at clinical follow-up were inconsistent.

This study helps us to identify areas for improvement in the education program. These include routine asthma action plan and ACT score to be performed in all education sessions and need for further pulmonologist education regarding the value of education. This highlights the need for continued physician education and reinforcement in completion of all aspects of asthma education program by the educators.

4.1. Future Trend. The cost-effectiveness of asthma education programs has been evaluated by several researchers. They concluded that education was cost-effective if it was able to decrease hospital admissions and income lost because of asthma [25, 26]. Larger studies are needed to evaluate the cost-effectiveness of programs with different structures in various population settings. Focus in those patients with frequent ER visits or admissions will be welcome.

\section{Conclusion}

In the management of asthma, implementation of a single adult asthma education session as part of physician visit had a positive impact on asthma control and healthcare utilization. We suggest that models like this could be easily developed in a socially disadvantaged population. Carefully chosen educators could minimize institutional cost, as they could fill other gaps in the patient care.

\section{Abbreviations}

ER: Emergency room

ACT: Asthma Control Test

PEFR: Peak expiratory flow rate

QoL: Quality of life.

\section{Disclosure}

The authors alone are responsible for the content and writing of the paper.

\section{Conflicts of Interest}

The authors report no conflicts of interest.

\section{References}

[1] 2014 National Health Interview Survey (NHIS) Data, National Center for Health Statistics, Center for Disease Control and Prevention, 2016.

[2] Centers for Disease Control and Prevention, Asthma FactsCDC's National Asthma Control Program Grantees, U.S. Department of Health and Human Services, Centers for Disease Control and Prevention, Atlanta, Ga, USA, 2013.

[3] 2016, Global Initiative for Asthma. Global Strategy for Asthma Management and Prevention, http://www.ginasthma.org.

[4] P. G. Gibson, H. Powell, A. Wilson et al., "Self-management education and regular practitioner review for adults with asthma (Review)," Cochrane Database of Systematic Reviews, vol. 3, Article ID CD001117, 2002.

[5] C. S. Ghosh, P. Ravindran, M. Joshi, and S. C. Stearns, "Reductions in hospital use from self management training for chronic asthmatics," Social Science \& Medicine, vol. 46, no. 8, pp. 10871093, 1998.

[6] A. Yilmaz and E. Akkaya, "Evaluation of long-term efficacy of an asthma education programme in an out-patient clinic," Respiratory Medicine, vol. 96, no. 7, pp. 519-524, 2002.

[7] M. A. De Oliveira, S. M. Faresin, V. F. Bruno, A. R. De Bittencourt, and A. L. G. Fernandes, "Evaluation of an educational programme for socially deprived asthma patients," European Respiratory Journal, vol. 14, no. 4, pp. 908-914, 1999.

[8] L. Ekerljung, B.-M. Sundblad, E. Rönmark, K. Larsson, and B. Lundbäck, "Incidence and prevalence of adult asthma is associated with low socio-economic status," Clinical Respiratory Journal, vol. 4, no. 3, pp. 147-156, 2010.

[9] E. Von Mutius, S. K. Weiland, C. Fritzsch, H. Duhme, and U. Keil, "Increasing prevalence of hay fever and atopy among children in Leipzig, East Germany," Lancet, vol. 351, no. 9106, pp. 862-866, 1998.

[10] C. Infante-rivard, "Childhood asthma and indoor environmental risk factors," American Journal of Epidemiology, vol. 137, no. 8, pp. 834-844, 1993.

[11] S. M. Stick, P. R. Burton, L. Gurrin, P. D. Sly, and P. N. LeSouëf, "Effects of maternal smoking during pregnancy and a family history of asthma on respiratory function in newborn infants," Lancet, vol. 348, no. 9034, pp. 1060-1064, 1996.

[12] T. A. E. Platts-Mills and M. C. Carter, "Asthma and indoor exposure to allergens," New England Journal of Medicine, vol. 336, no. 19, pp. 1382-1384, 1997.

[13] B. Brunekreef, D. W. Dockery, and M. Krzyzanowski, "Epidemiologic studies on short-term effects of low levels of major ambient air pollution components," Environmental Health Perspectives, vol. 103, no. 2, pp. 3-13, 1995.

[14] T. Volmer, "Socio economics of asthma," Pulmonary Parmacology \& Therapeutics, vol. 14, no. 1, pp. 55-60, 2001.

[15] New York Rankings Data Retrieved, http://www.countyhealthrankings.org/rankings/data/NY. 
[16] M. K. Paasche-Orlow, K. A. Riekert, A. Bilderback et al., "Tailored education may reduce health literacy disparities in asthma self-management," American Journal of Respiratory and Critical Care Medicine, vol. 172, no. 8, pp. 980-986, 2005.

[17] H. Moudgil, T. Marshall, and D. Honeybourne, "Asthma education and quality of life in the community: a randomised controlled study to evaluate the impact on white European and Indian subcontinent ethnic groups from socioeconomically deprived areas in Birmingham, UK," Thorax, vol. 55, no. 3, pp. 177-183, 2000.

[18] I. Poureslami, L. Nimmon, M. Doyle-Waters et al., "Effectiveness of educational interventions on asthma self-management in Punjabi and Chinese asthma patients: a randomized controlled trial," Journal of Asthma, vol. 49, no. 5, pp. 542-551, 2012.

[19] H. Powell and P. G. Gibson, "Options for self-management education for adults with asthma," Cochrane Database of Systematic Reviews, vol. 3, Article ID CD004107, 2002.

[20] J. De Miguel Díez, V. H. Barrera, L. P. Maestu, P. C. Garrido, T. G. García, and R. J. García, "Psychiatric comorbidity in asthma patients. Associated factors," Journal of Asthma, vol. 48, no. 3, pp. 253-258, 2011.

[21] J. Yorke, S. L. Fleming, and C. Shuldham, "Psychological interventions for adults with asthma," Cochrane Database of Systematic Reviews, vol. 1, Article ID CD002982, 2006.

[22] M. Thomas, S. Kay, J. Pike et al., "The Asthma Control Test ${ }^{\mathrm{TM}}$ (ACT) as a predictor of GINA guideline-defined asthma control: analysis of a multinational cross-sectional survey," Primary Care Respiratory Journal, vol. 18, no. 1, pp. 41-49, 2009.

[23] E. Mehuys, L. Van Bortel, L. De Bolle et al., "Effectiveness of pharmacist intervention for asthma control improvement," European Respiratory Journal, vol. 31, no. 4, pp. 790-799, 2008.

[24] M. C. Urek, N. Tudorić, D. Plavec, R. Urek, T. KoprivcMilenović, and M. Stojić, "Effect of educational programs on asthma control and qualitiy of life in adult asthma patients," Patient Education and Counseling, vol. 58, no. 1, pp. 47-54, 2005.

[25] M. S. Taitel, H. Kotses, I. L. Bernstein, D. I. Bernstein, and T. L. Creer, "A self-management program for adult asthma. Part II: cost-benefit analysis," The Journal of Allergy and Clinical Immunology, vol. 95, no. 3, pp. 672-676, 1995.

[26] R. Kauppinen, V. Vilkka, H. Sintonen, T. Klaukka, and H. Tukiainen, "Long-term economic evaluation of intensive patient education during the first treatment year in newly diagnosed adult asthma," Respiratory Medicine, vol. 95, no. 1, pp. 56-63, 2001. 


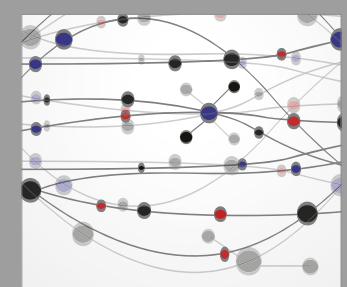

The Scientific World Journal
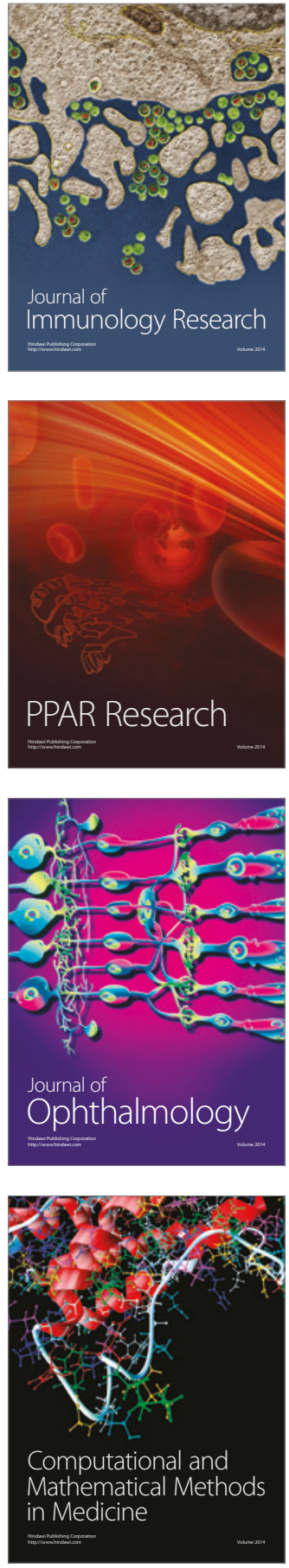

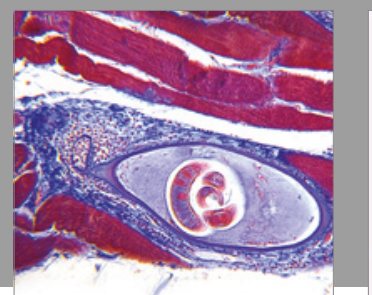

Gastroenterology Research and Practice
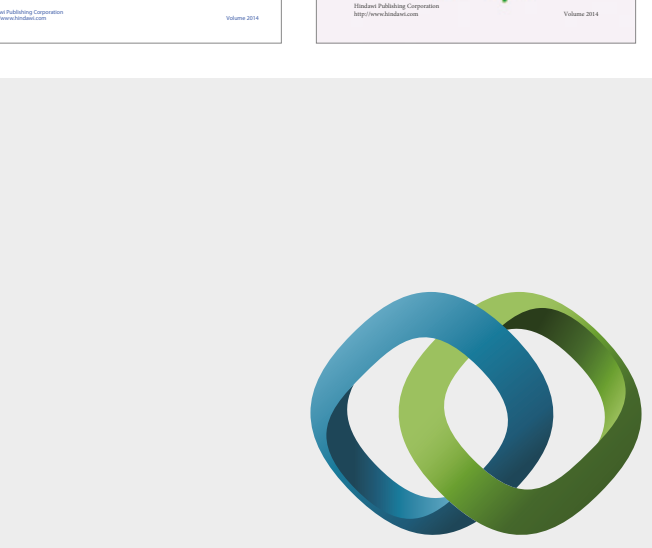

\section{Hindawi}

Submit your manuscripts at

https://www.hindawi.com
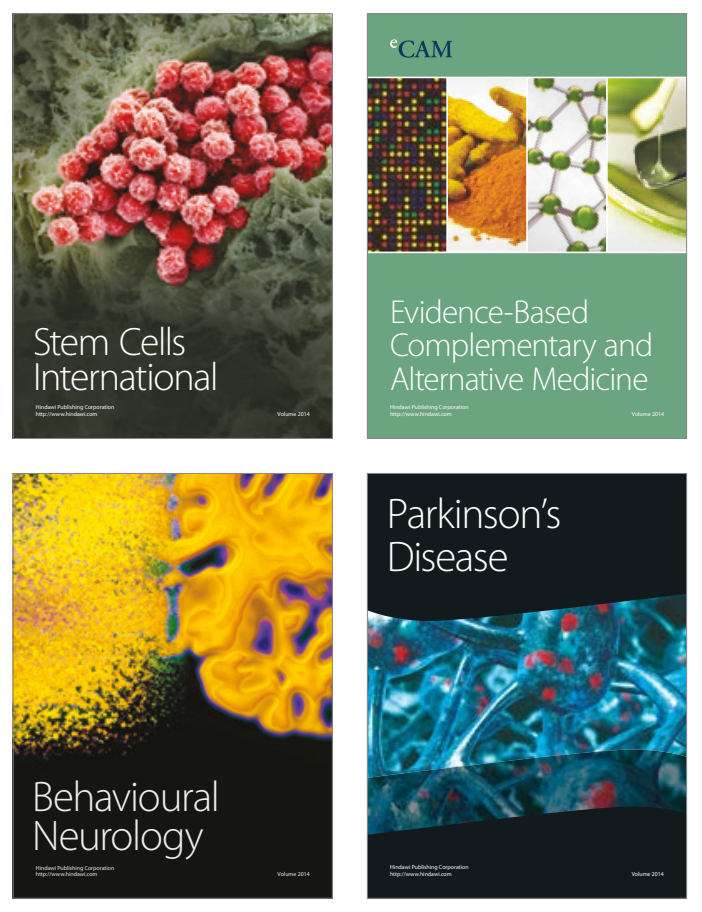
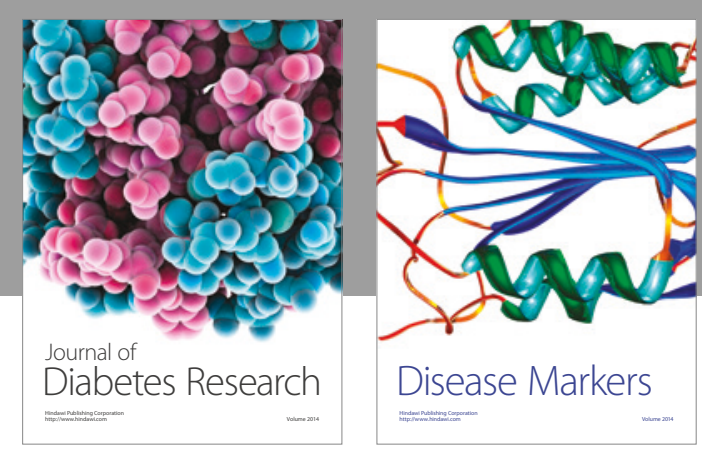

Disease Markers
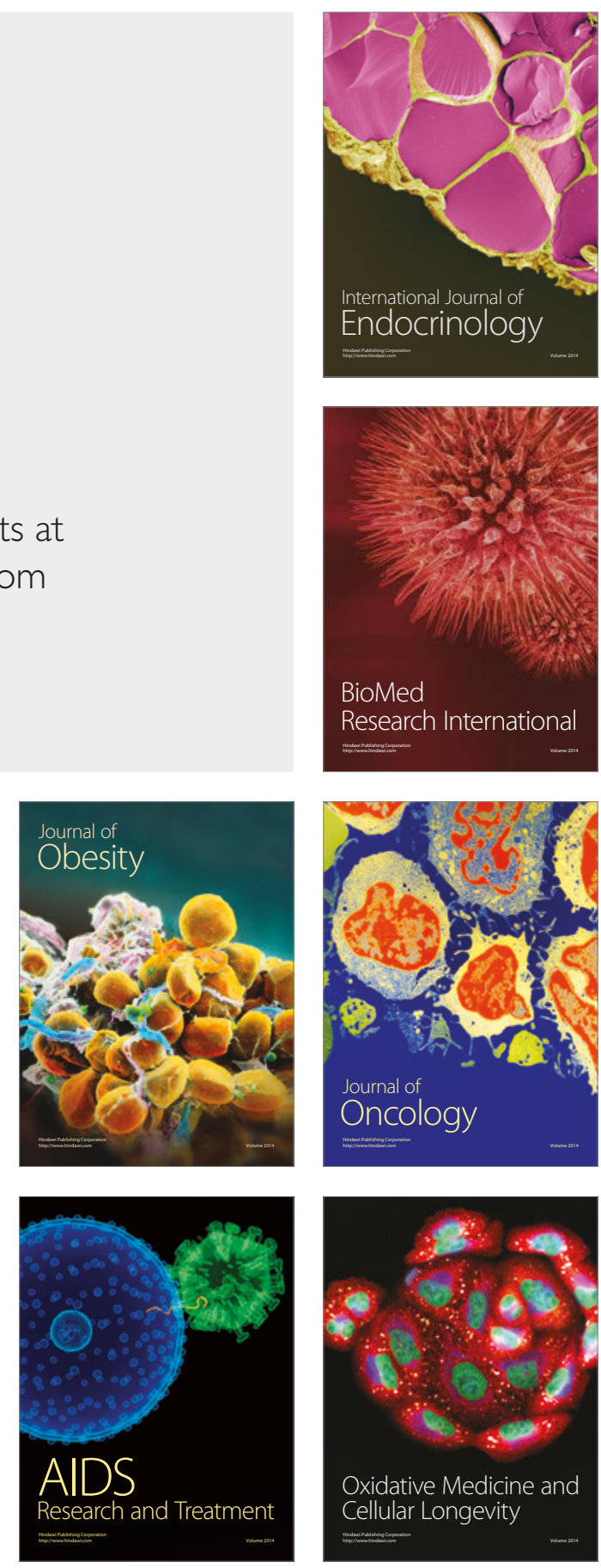